\title{
E-Graphic Novels
}

\author{
Benoît Crucifix \& Björn-Olav Dozo
}

authors' accepted manuscript - published in Jan Baetens, Hugo Frey, Stephen Tabachnick (eds.), The Cambridge History of the Graphic Novel, Cambridge University Press, 2018, p. 574-590.

\section{Resisting the Digital}

Cartoonists often appear as nostalgists, at odds with their times, practicing a seemingly obsolete but stubbornly persistent paper-and-ink craft. This somewhat clichéd view, already core to the figuration of underground cartoonists as Robert Crumb and Harvey Pekar, stands out even more clearly in the digital age, as wittily illustrated by Adrian Tomine's own portraits of the graphic novelist's everyday plight. In one of the various autobiographical gag stories included in his Optic Nerve periodical, fashioned in the format of an old-style 'floppy' comic book, Tomine wittily depicts the conundrum of the modern cartoonist faced with the 'digital revolution.' The page starts out on the familiar scene of the artist at his drawing table, typifying a material, physical creation acted out with specific tools and furniture. This classic representation of cartooning as métier is, however, a frustrated scene from the start: the paper is bleeding, it is impossible to ink properly, and the cartoonist is being failed by his old tools. As he interrupts work to search for a higher-quality drawing paper that does not bleed, the shop assistant at the art supply store advises him to try using a graphics tablet. Then going into a bookstore for a biography of post-war cartoonists Crockett Johnson and Ruth Krauss, the employee suggests to simply order it from Amazon. Eventually, Tomine tries to comfort himself by checking his P.O. box for 'thoughtful, hand-written' fan letters, but what he finds instead is an angry computer-typed note urging him to go digital. This exercise in self-mockery, typical for Tomine's posture (Schneider, 2016: 157-159), caricatures the ubiquitous resistance formulated by contemporary cartoonists against 'digital culture,' a wholesale opposition that is shared by many of Tomine's peers in their working techniques, publication choices, subject matter, and authorial ethos (Chute and Pagoda 2014).

As comics overtly assume their status as low-tech paper artifacts, the strength and 
near-ubiquity of this resistance to digitization cannot be understated. Jared Gardner convincingly argues that "of all the popular-culture media of the twentieth-century the one that has resisted complete digital translation most studiously remains comics" (Gardner, 2012: 192). Instead of moving on to screens, twenty-first-century comics have witnessed the institutionalization of the graphic novel as a successful publication model articulated around the book as material object. In spite of nearly three decades of dispersed digital experiments, and even though graphic novels are increasingly distributed through digital platforms, the e-graphic novel clearly remains an 'emergent' form. There are many interrelated reasons for this resistance, ranging from the institutional weight of large corporations on media convergence to the graphic 'site-specificity' of comics (Gardner, 2014). Likewise, the utopian promises of the digital failed to meet comics readers's expectations, as epitomized in the controversies generated by Scott McCloud's evangelical embrace of a 'digital revolution' in Reinventing Comics (2000).

By contrast, the print experiments of the graphic novel have precisely been exploring enhanced ways of engaging with narration and the book that cleverly display, in paper form, the modes of interactivity, multi-linear navigation and database logic associated with the "language of new media" (Manovich, 2001). This vitality of the graphic novel as print artifact is wittily expressed by Jan Baetens who contrasted Chris Ware's acclaimed graphic novel Jimmy Corrigan with the McCloud's limited embrace of digital comics as a mere expansion of linear, panel-to-panel sequentiality into an infinite canvas: "The first thing to notice about Jimmy Corrigan is that it is a heavy, old-fashioned, hard to handle, often difficult to read, book, but it nonetheless does exactly what McCloud wants his digital fiction to do in the near future" (Baetens, 2001). The papery multi-linear narration of Jimmy Corrigan, as illustrated in the large diagram foldout included in the hardcover version, quickly eclipses McCloud's "infinite canvas." Right at the turn of the century, then, the case of comics was posing a challenge to the logic of remediation described by Bolter and Grusin (1999).

Published twelve years after Jimmy Corrigan, Ware's widely acclaimed follow-up graphic novel Building Stories embodies even more powerfully this resistance against digitization by proposing a kind of "Kindle-proof literature" (Kashtan, 2015: 420). A box of fourteen items printed under various formats and to be read in any order, Building Stories conspicuously foregrounds its materiality, its papery 'body' (Ghosal, 2015), while preempting any facile adaptation to digital screens, and further develops within its pages an 
overt critique of digital devices. At the same time, however, the multi-directional, randomaccess, interactive structure of Building Stories invites to forms of reading and viewing typical of new media and Ware's work epitomizes this co-mingling of print materiality and "hyperreading" that characterizes the graphic novel (Kashtan, 2015; Orbán, 2014). The quick emergence of the graphic novel in the cultural landscape and within literary culture might be related to this exploration of reading practices that, if not new, have been increasingly foregrounded by digital media.

At the more hidden level of production, it is also important to underline that digital technologies underwrite the very possibility of graphic novels such as Building Stories in more implicit ways: digital tools and techniques of coloring, composition, imaging, and of course printing all feed into the production process, as comics follow in the large-scale "softwarization" of media of the twenty-first century (Manovich, 2013; Hayles, 2008). If many graphic novelists, like Tomine, stick to the 'old' nibs and brushes of traditional cartooning, the widespread digitalization of the means of comics production has led other cartoonists, such as Ben Katchor, to directly draw using a graphics tablet as a way to bypass the labor of turning original drawings on paper into print-ready digital files.

Besides this digitization of comics production, Building Stories further 'unbinds' the codex format, fragmenting the graphic novel into a variety of material supports in a quasi media archeological gesture (Crucifix, 2017). Part of the serialization of this work includes an installment first published as an interactive comic, entitled "Touch Sensitive," for McSweeney's iPad app: the premise was precisely to draw parallels between the 'touch' of the reader on the surface of the screen, and the everyday tactile gestures of the fictional couple as their relationship is deteriorating. As Kashtan argues, Ware's digital comic offered a critique of "the very technology with which it was created, pointing out the inability of digital devices to permit tactile interaction" (2015: 442). While the comic has been praised for making a powerful use of the specificities of its material support, Chris Ware himself voiced his discontent with this digital version. His next foray into digital serialization with "The Last Saturday" episodes published on a weekly basis at The Guardian Online conspicuously avoids any form of interactivity (apart from the invitation to "hover over image to zoom'), offering instead a traditional double-page grid that already announces its future inscription within a printed graphic novel. Where the first news of Chris Ware 'going digital' was announced as a signal for change, "The Last Saturday" speaks out a tamer, normalized 
relationship to the digital as a means for serializing graphic novels.

In this sense, Ware's piece is also symptomatic of the contemporary resurgence of serialization outside of traditional periodicals (the sales of which keep declining) and into the do-it-yourself spheres of zines, mini-comics and online platforms. This has already been the case in the distinct field of the comic strip (syndicated or not) since the 1990s: as its allocated space within the print newspaper kept shrinking, the comic strip quickly turned to the digital to find and build new audiences, at first catering to niche subcultures but quickly expanding (Kukkonen, 2014). Since then, webcomics appear as a relatively institutionalized form of digital comics that has successfully remediated the conventional newspaper comic strip. For alternative comics and graphic novels, while cartoonists like Chris Ware and Adrian Tomine - the "old guard" (Wolk, 2007: 365) - openly resist digitization, younger generations of graphic novelists adopt a much more relaxed approach to digital culture and increasingly serialize their short- and long-form comics through online venues: either through selfpublishing (blogs, tumblr, personal websites, mini-comics distributed through the Internet), or via dedicated media platforms as Vice, The Nib, GoComics, and others.

The book is no longer necessarily perceived as the working horizon, but rather confers prestige on cartoonists that have already proved successful online: this is, for instance, the case with graphic novels as James Kochalka's pioneering American Elf series (published online since 1998), Michael Deforge's Ant Comic, Jesse Moynihan's Forming, Dash Shaw's BodyWorld, Simon Hanselmann's Megg, Mogg and Owl, or Kate Beaton's Hark! A Vagrant. Online serialization also accompanies mini-comics or zines, either self-published or put out by the small press. This situation also parallels the French 'blog BD' phenomenon, with well-known figures as Pénélope Bagieu, Boulet and Lewis Trondheim, whose online blog comics are reprinted in book forms. This online serial lives of many graphic novels point out to what Baetens and Frey, following Marjorie Perloff, identified as the "differentialization of the graphic novel," referring to "differential texts" as "texts that exist in different material forms, with no single version being the definitive one" (Perloff quoted in Baetens and Frey, 2015: 107). Although some cartoonists erase the online installments once the book version is published, many graphic novels continue to exist both in digital and print formats, prompting different reading experiences. But while graphic novels rely more and more on digital serialization, the reverse process is also becoming increasingly important as print graphic novels are also often digitized and recirculated through digital channels. 


\section{Digitizing the Graphic Novel}

By the end of the 2000's, mainstream publishers had come up with several initiatives to distribute their comics in digital format, in an effort to expand their and invest the digital market. The main logic behind those efforts was the mimetic option of digitization: just as the Apple app iBooks recalled the physical materiality of print books by displaying e-books on wooden shelves, comics publishers followed the same mimetic strategy by trying to offer a digital reading experience based on print habits.

Responding to the development of "rogue archives" (De Kosnik, 2016) built by fans circulating digital, the core concern for publishers has been to translate their extensive catalogue into a digital format and to find out commercial models to monetize that access. Given the easiness of reproduction and replication in the digital context, where the difference between original and copy has no relevance, comics publishers opted for distribution platforms that would control to some extent the unwanted circulation of copyrighted works by relying DRM and streaming. Digital Rights Management indeed allows publishers to control what can be done with the file containing their comics: number of copies, reading formats, and so on. Streaming is even more constraining for consumers, who never really own the file itself but buy the right to access their library of comics online, at any time, through specific digital devices. Mainstream publishers thus increasingly bet on the strategy of subscriptions: for monthly fee, the reader has access to the entire catalog of one publishing house (at the beginning) or to various catalogs gather together on one platform, as ComiXology occupies the dominant position in the field. And so, the distribution model of digitized comics clearly move comics culture away from the collecting practices that have long defined it: as Gregory Steirer has argued, “[c]onsumers' inability to organise, display or sell their digital comics is thus a deliberate, top-down effort to produce a new kind of comics culture in which collecting [...] is effectively disabled" (Steirer, 2014: 11). While owning, collecting, displaying, and reselling are staved off by this subscription model, the existence of digital archives has also a direct impact on the market value of 'collectibles,' which makes access less exclusive while simultaneously increasing the attraction of owning the physical object.

Digital subscription models further provide publishers with a renewed platform for 
serialization, where sales of floppy comic books have been dwindling as readers are more and more directly turning to trade paperback and graphic novel editions. Digital platforms do not only grant access to vast catalogs, allowing fans to rediscover past issues and old narrative arcs, but simultaneously encourages them to follow the release of new episodes and installments: hence, such platforms are presumably very effective in encouraging and renewing serial affiliations by mixing access to large serial runs with 'digital-first' release of new periodical releases. Moreover, they also seek to draw in new audiences who have grown familiar with the storyworld through their transmedial franchises (Wershler, 2011: 131).

This renewed energy given to seriality through digitization is even more obvious when confronted with the phenomenon of scanlations (portmanteau for scanned and translated digital copies of comics, typically manga), as fans seek to make as soon as possible available new episodes of foreign series, responding to the somewhat slower rhythm of their official publications.1 Scanlations are but one example in the vast arrays of fan practices in the digital circulation and preservation of comics, even though these practices are effectively infringing copyright permissions and thus hard for scholars to map out, as they tend to be excluded by large data monopolies (Wershler, Sinervo and Tien, 2016; De Kosnik, 2016).

Besides the question of access, one of the important issues at stake for digitalizing enterprises was that of the reading experience. As the display of a print comics page on small screens raises questions of ergonomic efficiency, various platforms came up with solutions to offer a more fluid and comfortable reading experience, where the reader would not have to constantly zoom in and out or scroll up and down to be able to read it in details. In France, the pioneering platform was AveComics, an Aquafadas branch specialized in graphics softwares, and it emerged in direct competition with Izneo, which rose from a collective effort of various large comics publishers to digitize their catalog into an adapted reading interface. AveComics developed its own specific format - AVE stands for Adaptive Viewer Experience - which creates a stock out of the comics panels and offer two possible reading modes: a standard one, and an animated one, with automatic zooms, animations, sometimes even sounds and videos. The same strategy of 'enhancing' comics by digital means was explored by Marvel which, through its own app, besides granting online access

1 On the specificity of scanlations, see Douglass, Huber and Manovich (2011). 
to their vast catalog (thus allowing fans to rediscover missed fragments of various narrative arcs), also proposed to enhance the reading experience of their print comics through an augmented reality app: once pointed at a specific panel or page, the camera of the digital device used, whether a smartphone or a tablet, reveal on their screen a virtual enhancement of the printed comics. This technique was also explored by Belgian comics artist François Schuiten in La Douce, which reproduces in augmented reality a 1939 steam locomotive by aligning together the print album with the webcam 2 .

Besides promoting the idea of an enhanced digital experience, other platforms have attempted to translate the linearity and tabularity characteristic of the printed comics page (Fresnault-Deruelle, 1976), which can always be read sequentially and all at once, to the small frames of digital screens by relying on cinematic techniques that divide the page into 'Iong shots' (the whole page) and 'close-ups' (panels that are automatically sequentialized, mimicking the reader's gaze). This is the case of ComiXology's somewhat infamous 'Guided View' technology, which purports to replicate the reading experience and imitate the reader's eye wandering on the page, while simultaneously taking this action out of the reader's hand and into an automated reading software. Such remediation of the comics reading process was seen by many as a failure precisely because it implies an attempt to "make comics more like film and video games," and in so doing "reduces rather than augments the readers' agency and avenues for interaction with the form" (Gardner, 2014: 207-208).

This reduction of readers' agency is not only apparent in 'motion comics,' 'Guided View' technologies and the likes, but also results from the growing economic hegemony that a few actors hold on the whole field. Where there were several platforms for digital distribution in the early 2000s, the market has been increasingly centered into a few hands, themselves operated by large multinational companies: ComiXology was bought by Amazon, Marvel by Disney, DC by Warner Bros. Needless to say, such companies have a stronger interest in the development of large transmedia franchises, articulated around the film industry and encouraging readers to follow storyworlds across various media, than in the development of medium-specific digital comics. As in the case of movie adaptations, often borrowing typical features and visual strategies from comic books, the shift from page to

2 See www.12-ladouce.com/fr/la-realite-augmentee.html. 
screen for comics reading fronts a certain number of challenges that beg reconsideration.

\section{Born-Digital}

While the skeuomorphic persistence of print forms in digital comics seems to reign in experimentation with the specificities of the digital, there exists a large segment of borndigital e-graphic novels that explicitly attempt at doing things with comics that are not allowed by print technologies. In the same way as the graphic novel often relies on its medium-specific and haptic qualities, such e-graphic novels draws a conspicuous link between narrative, form and format. While close-readings of these digital experiments remain scarce, such works have often served as springboards for debates on the identity of comics as a medium (Wilde, 2015). The way digital screens transforms comics reading, in particular, has been met with skepticism. Trendsetting voices as Gary Groth (2001), JeanChristophe Menu (2011: 485-491), or Thierry Groensteen (2013) have variously expressed their distrust for the innovative potentials of comics. In an open-minded but skeptical discussion of comics, Groensteen has deplored that "the transformation of the ninth art into a hypermedium seems to run counter to one of its founding principles, which is the simultaneous display, and, therefore, immediate accessibility of its component parts" (Groensteen, 2013: 75-76).

Favoring layered juxtapositions and interactive sequencing, the computer screen indeed contrasts with the physical co-presence of images that otherwise makes print comics akin to an archive or database in paper form. As Magali Boudissa has argued, the "amnesia" of the computer screen entails a very different relationship to the arrangement of images: the panels are much less bound together by the physical unity of the page or the book, but are linked through a dynamic and fluid screen-image, changing at the speed of the reader's hand clicking, scrolling, tapping or swiping. The rhetoric and narrative effect of Stuart Campbell's praised e-graphic novel These Memories Won't Last (2016) brilliantly draws on this 'amnesia' of the screen to articulate a short autobiographical narrative on the author's grandfather's struggle with Alzheimer's disease: as the reader scrolls through the comic, the panels gradually fade away and become irretrievable. Campbell and his colleagues, Lhasa Mencur (sound design) and Vitaliy Shirokiy (programming), make use of digitally enabled tools to synchronize the movement of the reader's finger scrolling up and down the browser 
page with the appearance and disappearance of the panels as well as changes in the soundtrack. When representing the grandfather's troubled memories for dealing with present events, for instance, the scrolling movement disrupts the soundtrack which comes across as a broken recorded tape. The readers' hand movement is also recorded within the design of the narrative in the form of a continuous red thread that links the narrative captions, while the images are themselves all connected with a continuous rope, a kind of memory thread on which both characters and readers hold onto. At the same time, however, as the reader scrolls through the comic, lingering on each panel to decipher them, the image gradually and irretrievably fades away (Fig. 1). Just as the memories of the grandfather are becoming forgotten, the reader is directly confronted with the 'amnesia' of the screen as she cannot read again the panels that have faded and which are covered by a grey blur (unless she restarts her browser). Designed in html5, the comic itself has moreover been tailored for current web browsers across various devices, meaning that it is also dependent on the fast obsolescence of web technologies: future browser updates might hamper the functionality of the original code, gradually making these memories unreadable.

Fig. 1 Stuart Campbell, These Memories Won't Last, screenshot August 16, 2017.

\section{http://memories.sutueatsflies.com/}

Many born-digital graphic novels similarly rely on the interactive performance of the reader, who 'animates' the appearance and disappearance of panels in a way that has already been coded into the reading process by the creator and/or the interface:

The screen renews the narrative and aesthetic possibilities of comics by offering new dimensions to articulate panels: 'latent' temporality, infinite and malleable canvas, depth. Panels now possess an intermittent existence on the surface of the screen, creating a new poetics of appearance-disappearance (Boudissa, 2016: 88).

While Boudissa praises these new characteristics of the comics panel afforded by digital screens, Groensteen shivers at this "poetics of appearance-disappearance." As with cinema, the digitalization of graphic novels spurs critics and theorists to adopt pro- or contrapositions (Gaudreault and Marion, 2015; Marion, 2012). Aiming to pair narrative and format, e-graphic novels often challenge the conventional specificity of comics, blurring boundaries with other media through a process of hybridization (Rageul, 2014). 
Swimming in such murky waters, many theorists have attempted to map out digital comics with typologies accounting for their various forms, spanning distinct categories as scroll comics, hypercomics, webcomics, interactive comics, infinite canvas, and so forth (Batinić, 2016; Boudissa, 2016; among others). Theorists of digital comics, especially in France (Robert, 2016), have been particularly drawn to experimental examples that foreground the specificities of digital comics, sometimes narrowing the corpus down to media-conscious experiments. Following in on the strong semiological tradition of French comics theory, such theories attempt to redefine comics for the digital age, listing its characteristics and revising its system.

There is often an underlying sentiment that a thin boundary exists, keeping comics as a medium borrowing from but still distinct from animation and video games. The focus, however, remains on an attempt to outline how comics 'remain' comics in a digital media ecology. But to understand this medium-specificity of e-graphic novels, it seems precisely crucial to better grasp its place within a larger media-genealogical framework that pays attention to the history of intermedial relationships. French theorists of (digital) comics seem to have been resistant to bringing cinema and animation into the picture, perhaps by fear of its earlier sins of 'cinema-centrism' (Stefanelli, 2012). A book like Gaudreault and Marion's The End of Cinema (2015), which repeatedly evokes the digital graphic novel, powerfully illustrates the relevance of comics to cinema today. 3 In much the same way, American scholars as Scott Bukatman (2011), Jared Gardner (2012; 2014) and Joe SutliffSanders (2015), well-versed in film theory, impeccably manifest how understanding digital comics today requires us to take into account the the larger history of intermedial dialogues between comics, film, and animation. Bukatman unravels the "epistemological hesitation" that characterized both Winsor McCay's Little Nemo animated film and demian5. When I Am King scroll comic: the limited Flash animations might be far removed from the moving images of McCay's animation films, but both play on "surprise encounters" with moving images that "give them liveliness" (Bukatman, 2011: 142). In Projections, Gardner implies a larger historical narrative that replaces contemporary media convergence in the light of the early twentieth-century ties between comics and film:

3 See also the long-running seminar on film and comics at the annual Udine-Gorizia film studies conference (Quaresima et al., 2009). 
What we are witnessing today might be understood as something like a return to origins for both film and comics, or perhaps better put, a twenty-first-century recovery of a road-not-taken at the beginning of the twentieth century. Far from being an aberration or dilution of their 'true' formal properties, the convergence of film and comics can be understood as an embrace of the genetic links that once bound film and comics together when they emerged as the new media modes of storytelling in the early years of the twentieth century (Gardner, 2012: 181).

The advent of formats and technologies as the VHR, the DVD, and the many other visioning platforms profoundly changed the experience of film spectators by relocating cinema outside of the movie theater, also allowing them control over the rhythm of viewing, enhancing audience attraction and interaction. This is, to Gardner, what makes that "movies are learning how to be like comics all over again" (2012: 181).

This point ushers into one of the key issues raised by e-graphic novels: the capacity of users to determine the rhythm of their readings, an ability that had often precisely been contrasted with film-viewing. Philippe Marion (1997: 82-83) coined this difference between heterochrone - contexts in which the time of reception is defined by the reader (books, comics, photography) - and homochrone - contexts in which the time of reception is built into the medium (cinema, music). The digital, then, blurs such distinctions: film increasingly tends towards the heterochrone, while comics verge towards the homochrone. As already hinted at, it is precisely this change in the reading experience of comics that most challenge their medium identity, as Gaudreault and Marion asks: "Does the graphic novel lose its 'epiphany-like soul' when the possibilities introduced by the digital enable it to open up to movement and animation, and thus to the homochrone?" (Gaudreault and Marion, 2015: 80). E-graphic novels, though, often mix heterochrone and homochrone qualities by entitling the reader to 'set in motion' the still images: if the animated sequenced is programmed and coded into the interface by the creator, the reader is quite often given the role of the 'animator' through clicking, scrolling, swiping, and other movements that interactive egraphic novels require their readers to execute.

The way e-graphic novels introduce limited animations, then, is not necessarily antithetical to comics' fundamental reliance on the heterochrone: quite on the contrary, they precisely seem to recover a deep connexion with the optical toys of the late 
nineteenth-century that taught early audiences the mechanics of vision and perception fundamental to both film and comics (Gardner, 2012: 3-5). Indeed, one of the 'institutionalized' form of digital comics is reminiscent of the diaporama or the magic lantern: either sliding from still panel to still panel or from gifs to gifs. In the francophone world, this form has been coined as "turbomedia" by Balak in February 2009: originally based on Adobe Flash animations, the form now runs in HTML5. ${ }^{4}$ As early as 2012, Balak was recruited by Marvel to promote this format for Marvel Infinite Comics. Several cartoonists have adopted this form as a natural step for digital comics, privileging this intersection of comics, animation and diaporama. The main pitfall for the development and institutionalization of what some describe as a 'new medium' is the relative absence of a stable economic model to support its creation, unless a large publisher as Marvel decides to integrate it as part of its own distribution platform. If the graphic and narrative experimentation of turbomedia effectively blends several media, such works remain rather confidential as, without a specific market, they offer no outcomes for its creators, who often primarily work as graphic designers and animators.

The success of the turbomedia form can arguably be linked to its mix of heterochrone and homochrone quality, as the reader is always in control of his or her own reading rhythm, clicking through the panels, potentially back and forth. However minimal it can be, this limited form of interaction already hints at a connexion with video games, as the turbomedia form certainly parallels videoludic practices as the interactive film or the "playfilm" (Perron, 2002: 301). The border is thin between these two narrative forms that both limit the player or reader's interaction to a few clicks. But this interactive facet is explored even more in depth by many digital comics that attempt to introduce a 'play' element, bringing comics closer to video games by broadening the extent of the reader/player's role in shaping the narrative. Conflating theory and practice, Daniel Merlin Goodbrey (2014) has explored the connexions between comics and video games, advancing the term "game comics" to describe such digital hybridizations. Goodbrey's The Empty Kingdom, for instance, is distributed through a gaming platform, and works as a playable narrative where the reader is navigating through a comics page composing deserted landscapes - the empty kingdom. Anthony Rageul (aka Tony) has similarly developed the notion of an interactive

4 See Balak's blog (boubize.blogspot.be) or the collective TurboMedia page on Catsuka (catsuka.com/turbomedia/index.php). 
comic, both theoretically (Rageul, 2014), and in his own creations, such as Prise de tête (prisedetete.net), which require the reader to move the computer mouse around the screen to reveal clues and hints otherwise unavailable on a first reading, or sometimes to directly click and/or grab some elements (Fig. 2). Through her choices, the reader permanently restructures the layout of the comics page in a way that is always meaningful for the creator's narrative and aesthetic project. Calling on the reader to contemplate and move around the screen, Rageul's e-graphic novels certainly recall point-and-click games, where the player is invited to linger on a particular scene in order to find out 'where' to click and unlock the following stages.

Fig. 2 Anthony Rageul (Tony), Prise de tête, screenshot August 16, 2017. http://www.prisedetete.net/pdt/m04p0304.html

Besides the practice-based theoretical works of Goodbrey and Rageul, the connexions between video games and comics have been further been explored by Philippe Paolucci (2015) and Julien Baudry (2012). The latter has notably proposed an archeology of the historical relationships between comics and video games. In the late 1990s in France, several cartoonists have indeed sought an alliance with CD-ROM developing studios to experiment with interactive narratives: Benoit Sokal's L'Amerzone and the incidents of its development and distribution illustrate the hazards of pre-Internet graphics creation. Paolucci, for his part, investigates the question of adaption by focusing on the way the 'language of comics' is being reused within contemporary video games. And adaptation, as the site of dialogue between different media, is precisely a key point for the 'translation' of the graphic novel onto digital screens.

\section{From Here to Where?}

In lieu of a conclusion, Richard McGuire's Here offers a fascinating example of where comics might stand in digital culture today. The original idea, as it was drafted in the late 80s, to embed panels within panels to layer several moments of time happening in the same place was, as the story goes, inspired by a description of the Windows program McGuire heard from a friend (Smolderen, 2006: 23). In its 1989 publication in RAW already, "Here" proposed a narrative that was breaking down into so many temporal capsules dispersed across deep time that it resembled more effectively the 'database logic' that, according to 
Lev Manovich (2001), is taking over the traditional, cause-and-effect, linear narrative logic under the influence of new media. Comics are, according to some, distinctly apt to answer to this contemporary shift because of their affinity with such a database logic (Gardner, 2012), and 'Here' is certainly a momentous example of what a 'database comic' might look like. When reworked into a full-blown graphic novel in 2014, Here was simultaneously released as a digital app for tablets (iOS), which was not a simple digitization of the print book. Indeed, the digital version sought to draw its maximum potential from the non-linear and random structure characteristic of new media. Hence, where the graphic novel invests the print book as an architectural object by having the corner of the room coincide with the binding, the e-graphic novel explores the multi-panel interaction possible within the surface of the screen by partially randomizing each frame: the reader taps on the various 'windows' to make others appear, continuously recombining different moments in time within the same physical space. At each touch of the finger, a panel and a temporal moment are thus more or less randomly selected out of the large database of panels that makes up the totality of Here. Similarly, Richard McGuire and programmer Stephen Betts introduced tiny animated sequences in the form of GIFs, such as a cat licking his paw, subtly playing on the introduction of movement into otherwise static images, mixing heterochrone and homochrone qualities. The digital version thus powerfully 'translates' the basic concept of Here by adapting it into a medium-specific interface particularly suited to the ways comics seek to reposition themselves within digital culture. Released at the same time as the book, this 'adaptation' reverses any predominance of the print version over the digital one: both are seen as differential texts, using their own specific means to explore the past, present, and future of a single spot. This caseillustrates how graphic novelists, instead of nurturing an attachment to print culture that takes the digital as its opponent, might approach digital comics not necessarily for their own sake, but certainly for their own specificity.

\section{References}

Baetens, J. (2001) New = Old, Old = New. Electronic Book Review, January 1, www.electronicbookreview.com/thread/webarts/graphic.

Baetens, J. and H. Frey (2015). The Graphic Novel. An Introduction. New York: Cambridge 
University Press.

Batinić, Josip. (2016). 'Enhanced Webcomics': An Exploration of the Hybrid Form of Comics on the Digital Medium. Image [\&] Narrative 17(5): 80-91.

Baudry, J. (2012). Histoire de la bande dessinée numérique française. Neuvième art 2.0.: neuviemeart.citebd.org/spip.php?rubrique72.

Bolter, J. D. and R. Grusin. (1999). Remediation. Understanding New Media. Cambridge: MIT Press.

Boudissa, M. (2016). Typologie des bandes dessinées numériques. In P. Robert, ed., Bande dessinée et numérique, Paris: CNRS Éditions, 79-99.

Bukatman, S. (2011). Online Comics and the Reframing of the Moving Image. In D. Harries, ed., The New Media Book, London: British Film Institute Publishing, 133-143.

Chute, H. and P. Jagoda, eds. (2014). Comics \& Media, special issue of Critical Inquiry 40.

Crucifix, B. (2017). From Loose to Boxed Fragments and Back Again. Seriality and Archive in Chris Ware's Building Stories. Journal of Graphic Novels and Comics 8, doi: 10.1080/21504857.2017.1303619.

De Kosnik, Abigail. (2016). Rogue Archives: Digital Cultural Memory and Media Fandom. Cambridge: MIT Press.

Douglas, J., W. Huber and L. Manovich. (2011). Understanding Scanlation: How to Read One Million Fan-Translated Manga Pages. Image [\&] Narrative 12(1): 190-227.

Fresnault-Deruelle, P. (1976). Du linéaire au tabulaire. Communications 24.1: 7-23.

Gardner, J. (2012). Projections. Comics and the History of Twenty-First-Century Storytelling, Palo Alto: Stanford University Press.

Gardner, J. (2014). Film + Comics. A Multimodal Romance in the Age of Transmedial Convergence. In M.-L. Ryan and J.-N. Thon, eds., Storyworlds across Media. Towards a Media-Conscious Narratology, Lincoln: University of Nebraska Press, 193-210.

Gaudreault, A. and P. Marion (2015). The End of Cinema? A Medium in Crisis in the Digital Age. New York: Columbia University Press.

Ghosal, T. (2015). Books with Bodies: Narrative Progression in Chris Ware's Building Stories. Storyworlds 7(1): 75-99.

Goodbrey, D. M. (2015). Game Comics. An Analysis of an Emergent Hybrid Form. Journal of Graphic Novels and Comics 6(1): 3-14.

Groensteen, T. (2013). Comics and Narration. Trans. Ann Miller. Jackson: University Press of 
Mississippi.

Groth, G. (2001). McCloud Cuckoo-Land. The Comics Journal 232: 32-40.

Hayles, K. N. (2008). Electronic Literature: New Horizons for the Literary. Notre Dame: University of Notre Dame Press.

Kashtan, A. (2015). 'And it Had Everything in it': Building Stories, Comics, and the Book of the Future. Studies in the Novel 47(3): 420-447.

Kukkonen, K. (2014) Web Comics. In M.-L. Ryan, L. Emerson and B. J. Robertson, eds., The Johns Hopkins Guide to Digital Media, Baltimore: Johns Hopkins University Press, 521524.

Manovich, L. (2001). The Language of New Media. Cambridge: MIT Press.

Manovich, L. (2013). Software Takes Command. London: Bloomsbury.

Marion, P. (1997). Narratologie médiatique et médiagénie des récits. Recherches en communication 7: 61-88.

Marion, P. (2012). Emprise graphique et jeu de l'oie. Fragments d'une poétique de la bande dessinée. In E. Maigret and M. Stefanelli, eds., La Bande dessinée: une médiaculture, Paris: Armand Colin, 175-199.

McCloud, S. (2000). Reinventing Comics. How Imagination and Technology Are Revolutionizing an Art Form. New York: Harper Perennial.

Menu, J.-C. (2011). La Bande dessinée et son double. Langage et marges de la bande dessinée: perspectives pratiques, théoriques et éditoriales. Paris: L'Association.

Orbán, K. (2014). A Language of Scratches and Stitches: The Graphic Novel between Hyperreading and Print. In H. Chute and P. Jagoda, eds., Comics \& Media, special issue of Critical Inquiry, 40, 169-181.

Paolucci, (2015). La représentation de la bande dessinée dans le jeu vidéo: l'exemple de Comix Zone et XIII. In F. Barnabé and B.-O. Dozo, eds., Jeu vidéo et livre, Liège, Bebooks.

Perron, B. (2002). Jouabilité, bipolarité et cinéma interactif, In C. Vandendorpe and D. Bachand, eds., Hypertextes. Espaces virtuelles de lecture et d'écriture, Québec: Nota Bene, 285-311.

Quaresima, L., L. E. Sangalli and Federico Zecca, eds. (2009). Cinema e fumetto. Cinema and comics. Udine: Forum Edizioni.

Rageul, A. (2014). La Bande dessinée numérique, figures et tensions d'un médium hybride. In L. Gerbier, ed., Hybridations. Les rencontres du texte et de l'image. Tours: Presses 
universitaires François-Rabelais, 2014.

Robert, P., eds. (2016). Bande dessinée et numérique. Paris: CNRS.

Schneider, G. (2016). What Happens When Nothing Happens. Boredom and Everyday Life in Contemporary Comics. Leuven: Leuven University Press.

Smolderen, T. (2006). An Interview with Richard McGuire. Comic Art 8: 14-39.

Sutliff-Sanders, J. (2015). Valentine, Comics for Mobile Devices, and the Limits of Empowerment. In J. Cañero and E. Claudio, eds., On the Edge of the Panel: Essays on Comics Criticism, Newcastle: Cambridge Scholars, 174-194.

Stefanelli, M. (2012). Du "cinéma-centrisme" dans le champ de la bande dessinée.

L'influence du cinéma sur la théorie et la pratique du "9e art." In E. Maigret and M.

Stefanelli, eds., La Bande dessinée: une médiaculture, Paris: Armand Colin, 217-236.

Tomine, A. (2013). Optic Nerve \#13, Montreal: Drawn and Quarterly.

Ware, C. (2012). Building Stories. New York: Pantheon.

Wershler, D. (2011). Digital Comics, Circulation, and the Importance of Being Eric Sluis. Cinema Journal 50(3): 127-134.

Wershler, D., K. Sinervo and S. Tien (2016). A Network Archaeology of Unauthorized Comic Book Scans. Amodern 2: amodern.net/article/a-network-archaeology-of-unauthorizedcomic-book-scans/.

Wilde, L. (2015). Distinguishing Mediality. The Problem of Identifying Forms and Features of Digital Comics. Networking Knowledge 8(4): 1-12.

Wolk, D. (2007). Reading Comics: How Graphic Novels Work and What They Mean. Philadelphia: Da Capo Press. 